\title{
Contents of the Following Issues of Opticheskiu Zhurnal (Journal of Optical Technology)
}

PACS numbers: 01.10.Cr

DOI: $10.1134 / \mathrm{S} 0030400 \mathrm{X} 0803020 \mathrm{X}$

The following papers will be published in the March issue of Opticheskil Zhurnal (Journal of Optical Technology), vol. 75, no. 3, 2008.

Physical Optics. Measuring the Femtosecond Pulse Parameters within a Wide Spectral Range Based on the Effect of Multiphoton Absorption in a Natural Diamond Crystal (S.V. Gagarskiı̌ and K.V. Prikhod'ko); A Method for Direct Measurement of the Doppler Shifts and Zeeman Effect from Solar Optical Digital Spectrograms and Long-Period Oscillations of Sunspots (V.I. Efremov, L.D. Parfinenko, and A.A. Solov'ev); Relationship between a Relative Interference Fringe Shift, Refractive Index of a Metal, and Light Absorption by a Semitransparent Metal Layer (E.S. Kulagin).

Computation, Design, and Manufacture of Optical Systems. A Gradient Method for the Computation of Optical Elements Forming a Preassigned Illuminance on a Curved Surface (A.A. Belousov, L.L. Doskolovich, and S.I. Kharitonov); Reciprocal Mapping of the Object Space and Visible Image Space (G.K. Potapova and M.A. Moskalenko).

Iconics: The Science of Images. Study of the Statistical Characteristics of 3D Object Envelopes (N.N. Krasil'nikov and O.I. Krasil'nikova).

Holography. Sensitivity of Volume Holographic Media (B.S. Gurevich, S.B. Gurevich, and A. Petskus); Croconic Dye as a Sensitizer of Photothermoplastic Holographic Media for the Near-IR Spectral Range (N.A. Davidenko, A.A. Ishchenko, Yu.P. Get'manchuk, N.A. Derevyanko, L.I. Kostenko, A.V. Kulinich,
V.V. Kurdyukov, E.V. Mokrinskaya, L.N. Gumenyuk, V.A. Pavlov, N.G. Chuprina, N.N. Kuranda, and S.V. Khutorny $)^{\text {). }}$

Optical Instrumentation and Technology. A Series of Silicon Multiplexers for CdHgTe Photodiodes for the 8-16- $\mu \mathrm{m}$ Spectral Range (A.I. Kozlov, I.V. Marchishin, V.N. Ovsyuk, and A.L. Aseev); A System for the Remote Optical Monitoring of the Cross Section of a Railway Aerial Contact Wire (V.S. Bazin, A.G. Verkhoglyad, I.A. Vykhristyuk, S.V. Kalichkin, V.É. Kalikin, S.N. Makarov, M.F. Stupak, and Yu.V. Chugu1̌).

Optical Materials Science and Technology. Physicochemical Methods for Enhancing the Thermal Strength of $\mathrm{LiYF}_{4}: \mathrm{Nd}$ Laser Crystals (A.I. Ignat'ev, N.V. Nikonorov, I.V. Mochalov, E.V. Tsygankova, V.M. Reiterov, and A. Baltushka).

Practical Manufacturing Problems. A Setup for Measuring Spectral Coefficient of Directional Transmission of Large-Aperture Optical Elements (E.I. Dmitriev, O.K. Filippov, and V.G. Filippov); Optical Position Angle Sensor of the ZA-320M Automated Telescope at the Pulkovo Observatory (A.V. Devyatkin, A.P. Kulish, A.V. Shumakher, I.A. Vereshchagina, V.V. Kupriyanov, and A.S. Bekhteva).

Compiled by $\boldsymbol{L}$. V. Enushevskaya Translated by S. Belov 